

\title{
Repercussões do cenário contemporâneo no ato de compartilhar refeições em família
}

\section{The influence of the contemporary scenario on the meal sharing amid families}

\author{
Isabel Kasper Machado ${ }^{[a]}$, Débora Becker ${ }^{[b]}$, Débora Martins de Campos ${ }^{[b]}$, \\ Guilherme Welter Wendt ${ }^{[\mathrm{cl}}$, Carolina Saraiva de Macedo Lisboa ${ }^{[\mathrm{d}]}$
}

\footnotetext{
${ }^{\text {[a] }}$ Mestre em Psicologia pela Universidade do Vale do Rio dos Sinos (Unisinos), São Leopoldo, RS - Brasil, e-mail: isakasper@hotmail.com

${ }^{[b]}$ Graduadas em Psicologia pela Universidade do Vale do Rio dos Sinos (Unisinos), São Leopoldo, RS - Brasil, e-mails: becker.dek@gmail.com; deborahada@gmail.com

${ }^{[c]}$ Bacharel em Psicologia pela Pontifícia Universidade Católica do Rio Grande do Sul (PUCRS), doutorando em Psicologia (Goldsmiths, University of London - Bolsista CAPES), London - UK e-mail:

guilhermewwendt@gmail.com

${ }^{[\mathrm{d}]}$ Doutora em Psicologia, professora da Pontifícia Universidade Católica do Rio Grande do Sul (PUCRS), Porto Alegre, RS - Brasil, e-mail: lisboacaro@gmail.com
}

Recebido: 20/03/2012 Received: 03/20/2012

Aprovado: 20/11/2012 Approved: 11/20/2012

\section{Resumo}

O presente artigo teve por objetivo discutir as transformações que o ato de se alimentar em família sofreu nas últimas décadas. Com este propósito, discorre-se sobre as influências econômicas e tecnológicas que provocaram variações de comportamento e dos valores na sociedade e, por consequência, na organização do grupo familiar, envolvendo, entre outros processos, a alimentação. Buscou-se fazer leituras que primeiramente auxiliassem a compreensão do ato de alimentar-se, considerando a influência de fenômenos de ordem cultural e histórica, como a industrialização, a crescente urbanização e até mesmo as guerras. A literatura tem sinalizado modificações importantes na família, especialmente em hábitos relacionados à alimentação e aos aspectos emocionais devido às mudanças na sociedade contemporânea. Muito embora esteja claro para os pesquisadores que a comensalidade exerça um papel protetivo para a saúde física e mental dos indivíduos, o que se constata é um crescente aumento da alimentação em restaurantes e lanchonetes, ou seja, fora de casa, o que, em geral, é inadequado e nocivo à saúde. Percebe-se que as famílias convivem com um excesso de informações sobre alimentação saudável e não saudável e têm rotinas desregradas em função de elevadas e crescentes demandas sociais e profissionais. Pesquisadores apontam que os encontros familiares reduziram e este fato pode repercutir nas escolhas e práticas alimentares. Programas interdisciplinares de intervenção com famílias que considerem o cenário atual ainda são escassos, mas extremamente necessários. Sugestões para investigações futuras são apresentadas e discutidas.

Palavras-chave: Família. Comportamento alimentar. Comensalidade.

\section{Abstract}

This paper aimed to discuss the transformations that the habit of eating with the family suffered in the last decades. For this purpose, technological and economic influences responsible for society behaviors and values variations, as well as accounting for changes in family organization involving eating are described. The readings focused on the comprehension of the eating act, taking into account the influence of cultural and historical phenomena as industrialization, growing urbanization and even wars. The literature presents significant changes in families nowadays, especially in relation to eating habits and emotional aspects, due to contemporary society

Psicol. Argum. 2014 jan./mar., 32(76), 117-127 
changes. Therefore it is already a consensus to researchers that commensality is a protective factor to human's physical and mental health, what one observes is an increase of the habit of eating at restaurants and snack bars, in other words, outside home, what is inadequate and risky for health. Something observed is that families receive excessive information about healthy and non healthy habits and have disorderly routines because of increasing social and professional demands. Researchers evidenced that familiar reunions are not so common nowadays and that this fact may reverberates in the eating choices and practices. Interdisciplinary programs for families that take into account the actual scenario are still rare although extremely necessary. Suggestions for future investigations are presented and discussed.

Keywords: Family. Feeding Behavior. Commensality.

\section{Introdução}

Os indivíduos, assim como as famílias, sofrem influências de elementos econômicos e sociais, que provocam variações de comportamento e dos valores em seus membros (Meira \& Centa, 2003). Nesta dinâmica, as modificações socioculturais atingiram a rotina familiar e todos os elementos presentes neste contexto, como os hábitos e comportamentos relacionados à alimentação. Atualmente, as famílias muitas vezes não conseguem compartilhar refeições e os fatores causais desse processo estão relacionados aos compromissos profissionais e pessoais, às distâncias nos grandes centros urbanos e dificuldades no trânsito (Rossi, Moreira \& Rauen, 2008).

0 crescimento urbano, o desenvolvimento industrial e a entrada da mulher no mercado de trabalho impulsionaram um rápido desenvolvimento no setor de restaurantes, criados para suprir a necessidade das pessoas que não têm tempo de preparar as refeições em casa e tampouco para compartilhar esses momentos. Diante dessa nova realidade, as famílias precisaram se reorganizar, o que implica consequências emocionais, comportamentais e nutricionais, que ainda não podem ser descritas com detalhes e precisão (Collaço, 2004).

Nesse sentido, o presente artigo tem como objetivo apresentar e problematizar as transformações sobre o ato de se alimentar em família, abordando a comensalidade e suas consequências contemporâneas. Para uma adequada contextualização acerca do tema e para uma compreensão ampliada sobre os comportamentos e crenças envolvidos nesse processo, realizou-se uma revisão crítica e não sistemática da literatura que versa sobre alguns acontecimentos históricos e suas possíveis influências sobre as formas de alimentar-se na atualidade. Assim, buscaram-se produções teóricas e empíricas em diferentes áreas, como da psicologia, história, nutrição, sociologia, entre outras.

\section{Desenvolvimento}

Partindo do pressuposto de que a fome é uma necessidade natural que impulsiona a motivação alimentar e deve ser satisfeita pela ingestão de alimentos para assegurar a existência humana, o ato de alimentar-se transcende as características biológicas e as estritamente ligadas à sobrevivência. Isso decorre uma vez que as práticas alimentares situam-se na esfera da cultura e têm inúmeros significados sociais e emocionais (Romanelli, 2006), que impactam nos hábitos e preferências alimentares das pessoas (Ornelas, 2003). 0 ato de alimentar-se, de acordo com Garcia (1997), está relacionado a diversos significados. A dimensão afetiva relacionada à alimentação, envolvendo assim a relação com o outro, está presente nas refeições familiares e é neste meio, juntamente com o envolto social e histórico, que as pessoas irão formar as crenças e representações mentais relacionadas aos hábitos alimentares (Romanelli, 2006). São as famílias que transmitem aos seus membros estes significados culturais, sociais e os valores individuais relacionados à alimentação, nutrição e hábitos.

As escolhas alimentares consistem num fenômeno amplo, associado ao jogo múltiplo de atrações e repulsas, fundado nos hábitos da infância e também associado às lembranças de cada indivíduo. Em razão do olfato, pode-se apreciar o aroma de bebidas e alimentos, pois este é o sentido que está mais associado ao sistema límbico, encarregado pelo 
gerenciamento das emoções e memórias (Malnic, 2008).

A forma como o alimento é oferecido e apresentado também influencia nas escolhas e preferências (Souza, 2001). Além disso, conforme acrescenta Viana (2002), o paladar, o preço, o aspecto/apresentação, a facilidade no preparo, a publicidade, entre outros, são aspectos que condicionam as escolhas alimentares, mais do que propriamente o conhecimento dos benefícios para a saúde. Os alimentos estão associados ao prazer, sabores, cheiros, e induzem a determinadas emoções e comportamentos, muitas vezes, imperceptíveis pelo indivíduo (Malnic, 2008). Pelo olfato, pode-se perceber a diferença de sabores e por meio dele é que a memória de muitos pratos pode ser evocada. Assim, o prazer de saborear uma deliciosa receita funde-se às companhias associadas a tal ato, relembrando, através da alimentação, aspectos emocionais e históricos, os quais são imprescindíveis para o desenvolvimento humano saudável. A sociedade passou por grandes transformações para chegar ao estágio em que se encontra $\mathrm{o}$ ato de alimentar-se, principalmente com o surgimento dos primeiros restaurantes. A partir da Revolução Francesa, muitos chefs que trabalhavam para a aristocracia francesa ficaram desempregados, sendo obrigados a dedicar-se ao próprio negócio (Pitte, 1998; Strong, 2004). Por outro lado, o processo de industrialização estava aquecido na Europa, o que permitiu o surgimento de pequenos "bistrôs", cuja função era fornecer refeições com preço razoável aos trabalhadores que precisavam comer próximo ao trabalho (Pitte, 1998).

No Brasil, a criação de pequenos restaurantes teve início um pouco mais tarde, no despertar do século XIX, embora com a mesma demanda e motivações. Como os trabalhadores das indústrias não podiam mais ir para casa na hora do almoço, lanchonetes e restaurantes passaram a servir comida caseira nas proximidades das fábricas. Esta solução atendia às necessidades por um valor acessível. Assim, a criação dos parques industriais provocou não só mudanças econômicas e tecnológicas, mas também alterou a rotina dos hábitos alimentares das pessoas (Freixa \& Chaves, 2008).

As distâncias ficaram maiores entre o campo e o consumidor, pois o aumento da industrialização e das novas tecnologias na produção de alimentos colocou o homem distante da cadeia produtiva. A industrialização propiciou a evasão do cidadão que cultivava a terra para as grandes cidades e a Grã-Bretanha, no final do século XIX, verificou claramente essa mudança, quando a maior parte da população já tinha abandonado a agricultura para dedicar-se à indústria, fazendo que as famílias trocassem a vida no interior pelas cada vez mais movimentadas cidades (Fernandez-Aemestro, 2004; Poulain, 2004).

As guerras também contribuíram com essas mudanças, fazendo que o indivíduo procurasse outros métodos para a produção e armazenamento dos alimentos, já que havia a necessidade de prover alimentação para um grande número de pessoas em um mesmo local e também alternativas restritas para o seu preparo. As fábricas alimentícias passaram a produzir e fornecer produtos em grande escala e este fato propiciou o desenvolvimento dos enlatados e embutidos em geral (Fernandez-Armesto, 2004).

Associado às mudanças e à necessidade das pessoas, as técnicas de preparo dos alimentos e a maneira de servir também começaram a mudar com o avanço da tecnologia. Um exemplo disso foi a troca do antigo fogão a lenha pelo fogão a gás, o que facilitou e agilizou os processos dentro da cozinha. Segundo Silva (2007), no início do século XX, as companhias de gás no Brasil dirigiam as propagandas sobre a aquisição de fogões como uma fonte de economia de tempo e dinheiro. 0 preparo das refeições já não exigia mais tanto tempo de preparo, tornando os processos mais rápidos.

Além deste fato, precisamente no ano de 1914, o renomado chef francês Escoffier, seguindo a tendência da velocidade observada pelo advento da televisão e do telefone, reestrutura a maneira habitual de servir as refeições para uma quantidade menor, sendo as refeições apresentadas e preparadas de uma maneira mais rápida (Strong, 2004). Já o advento da refrigeração propiciou que os alimentos passassem a ser conservados por mais tempo. Não era mais preciso abater um animal próximo ao consumo, pois sua carne poderia ser conservada e armazenada sem riscos de estragar (Pedrocco, 1998). Segundo Mintz (2001), na contemporaneidade, grande parte da população mundial não produz $o$ que consome, por vezes, não consome o que produz. Em algumas situações, o consumidor dificilmente conhece a procedência dos alimentos ou se é a esta-ção de determinada fruta, por principalmente nas indústrias, é realizada em uma escala de velocidade

Psicol. Argum. 2014 jan./mar., 32(76), 117-127 
e quantidade que a percepção de consumo se esconde e se dilui. Conforme Bauman (2008), a sociedade de consumo deseja satisfazer os desejos humanos em um grau nunca antes alcançado, e é a constante insatisfação dos desejos que torna o consumo tão sedutor.

Todas essas mudanças contribuíram para uma série de modificações nos hábitos alimentares da humanidade, incluindo a escolha dos alimentos e locais das refeições. Pouco salientadas, mas não menos importantes, são as modificações comportamentais e cognitivas que acompanham e surgem a partir destes acontecimentos sócio-históricos. No princípio do século XXI, a exigência é de velocidade e aceleração do tempo, o que requer uma alimentação rápida. 0 termo utilizado para este tipo de alimentação é denominado fast food.

Consequentemente, o crescimento das lanchonetes propicia a substituição dos carboidratos complexos (cereais, amidos) por carboidratos simples (açúcares e gorduras), com resultados não satisfatórios para a saúde física e, consequentemente, a mental (Rial, 2006). 0 tipo de alimentação moderna nas grandes cidades não pôde mais se manter dentro do mesmo funcionamento de antigamente (Garcia, 1997). Neste contexto, as pessoas passam a valorizar alimentos que estejam prontamente disponíveis para que sejam rapidamente ingeridos, sem atrapalhar as demais atividades da rotina. Logo, refeições compartilhadas e feitas nas residências diminuem em frequência.

Além disso, o fast food, originário dos Estados Unidos, imprimiu mais velocidade à alimentação, o que transformou/resumiu o hábito de alimentar-se em um comportamento ágil e prático. Passada a grande recessão econômica, a partir da década de 1950, a família norte-americana conseguiu comer fora de casa, mesmo que essa refeição fosse um lanche rápido. Neste contexto histórico e social, alimentar-se fora do ambiente doméstico era um indicador de que a família tinha recursos financeiros para isso. Simultaneamente, este comportamento familiar passou a ser reconhecido e associado a status (Mintz, 2001).

São diversos os aspectos que envolvem e atravessam o interesse por alimentos de preparo rápido. Para Ortigoza (1997), o fast food adequa-se às necessidades das grandes cidades, uma vez que atende aos preceitos de velocidade com a qual seus moradores estão acostumados a viver. 0 mesmo autor menciona o impacto da globalização na maneira de comer, ou seja, o que se consome no Brasil pode ser consumido em outras partes do mundo, fazendo que as pessoas tenham a sensação, por meio da alimentação fast food, de pertencimento ao mundo. Em um estudo realizado por Garcia (2003), constatou-se que os brasileiros valorizam o modo norte-americano de realizar as refeições, relacionando o fast food como sinônimo de contemporaneidade e modernidade, ou seja, como marca ou algo de primeiro mundo.

Dessa maneira, a necessidade de comer fora de casa nos grandes centros urbanos - já que não era viável deslocar-se até a residência para almoçar em função de expressivas distâncias -, associada às dificuldades relativas à imposição dos horários de trabalho, acabou modificando a rotina da alimentação (Garcia, 1997). Entretanto, diversos autores (Mintz, 2001; Ortigoza, 1997; Rial, 2006) assinalam que essa mudança foi motivada também por outras questões, entre elas o status de comer fora de casa e o "pertencimento ao mundo", ou seja, por compartilhar hábitos da modernidade, como anteriormente salientado.

No Brasil, observou-se que, a partir do final da década de 1980, ocorreu um aumento do público que passou a almoçar fora do lar, com a expansão de restaurantes de buffet. Até então, predominavam as refeições feitas em casa, principalmente nas pequenas e médias cidades brasileiras (Abdala, 2009). 0 buffet ou self-service é um serviço no qual o estabelecimento oferece, em uma mesa ou balcão, uma variedade de alimentos; cabe, então, ao cliente, escolher e servir-se daquilo que irá ingerir (Lôbo, 1999).

Desde o final do século XIX, uma tríplice composta por industrialização, racionalização e funcionalização crescente passou a reger as inquietações da vida moderna dos indivíduos e de suas famílias (Soares, 2004). Em decorrência disso, os hábitos alimentares acompanharam esse movimento e também receberam as devidas interferências.

Na década de 1980, todavia, surge um novo movimento, chamado slow food. Iniciado na Itália, esse fenômeno atualmente é difundido em toda a Europa, principalmente nos países de língua latina (Rocha \& Neto, 2005). Este movimento está associado a ideias contrárias à "pressa" e à "loucura da globalização"; simultaneamente, haveria uma valorização da qualidade e do saborear da comida 
em detrimento da pressa que se tem em ingeri-la (Rocha \& Neto, 2005).

As transformações no preparo dos alimentos e no ato de alimentar-se não trouxeram apenas consequências para o comportamento, mas também para a qualidade do que é ingerido. Além disso, introduziram variadas mudanças na concepção do que é saudável, e foram diversos os efeitos sobre a saúde. Nesse sentido, avançamos agora para a discussão das modificações referentes aos aspectos nutricionais.

Em relação a esses aspectos, cabe mencionar que o arroz, o feijão e a farinha de mandioca foram a base da alimentação do brasileiro durante muitas décadas. Entretanto, esses itens têm sido substituídos por produtos industrializados, com maior valor agregado e, muitas vezes, com baixo conteúdo nutricional (por exemplo, batata frita, lanches rápidos e ricos em gordura, guloseimas, entre outros). Diante disso, pode-se assinalar que a necessidade do consumo rápido e a busca por praticidade induzem a uma alimentação inadequada e desprovida dos nutrientes necessários, estando presente em diferentes níveis socioeconômicos (Santos, 2005).

Os padrões alimentares, os costumes e os hábitos alimentares se modificam, com uma preferência pelo fast food (Santos, 2009). Os restaurantes passaram a diminuir a oferta de pratos, facilitaram o atendimento e assim diminuíram os preços, sendo o fast food uma atrativa opção da classe média para as refeições fora de casa. Denota-se que esta escolha não foi somente dos trabalhadores, mas também das famílias que não tinham recursos para comer fora de casa. A oportunidade de vislumbrar um novo mundo desenvolveu novas situações e, assim, novos hábitos alimentares desconhecidos até então (Bezerra \& Sicheri, 2010).

Além dos significados valorativos que o fast food conquistou nos últimos tempos, é necessário identificar quais nutrientes as pessoas ingerem quando consomem este tipo de alimentação. Conforme Ortigoza (1997), os alimentos oferecidos por essas redes não são refeições completas, pois, além de serem hipercalóricos, têm poucas vitaminas e inúmeros conservantes. Portanto, não serviriam como alimentos saudáveis para serem incluídos na alimentação diária. Estas constatações preocupam profissionais da saúde e demandam políticas públicas que possam auxiliar na ressignificação e crítica do valor subjetivo positivo atribuído à alimentação do tipo fast food.
Inúmeros estudos (Garcia, 1997; Garcia, 2003; Santos, 2003) assinalam que a ingestão de alimentos hipercalóricos e ricos em gorduras, com índices insuficientes de vitaminas e minerais essenciais acarretam em enfermidades diversas, entre elas problemas cardiovasculares, diabetes, obesidade e sobrepeso. Relatórios de investigadores da área da saúde e de órgãos governamentais (IBGE, 2006; Vigitel Brasil, 2009) têm apresentado números preocupantes da ocorrência dessas doenças na população brasileira.

A obesidade, o sobrepeso e as patologias associadas à alimentação não são foco desta revisão teórico-crítica; entretanto, a seguir serão apresentados índices de tais problemáticas justamente para embasar a necessidade de trabalhos, investigações e intervenções que possam orientar quanto à necessidade do consumo de alimentos saudáveis e sobre os prejuízos quando tais recomendações não são respeitadas. Ao tratar da alimentação dos seres humanos, deve-se ter atenção sobre a importante participação dos aspectos afetivos, cognitivos e comportamentais envolvidos nessa atividade que podem implicar em resultados nocivos à saúde (por exemplo, a valorização do fast food aliada à escassez de nutrientes importantes para o metabolismo saudável do corpo humano).

Conforme o relatório do Ministério da Saúde (2009), houve um aumento progressivo da obesidade entre os brasileiros, sendo que $13 \%$ dos adultos são obesos. Esse percentual era de 12,9\% em 2007 e de 11,4\% em 2006. Segundo a pesquisa, o índice de obesidade é maior entre as mulheres $(13,6 \%)$ do que entre os homens (12,4\%). 0 índice de brasileiros com excesso de peso, no entanto, apresenta estabilidade nos últimos três anos. Nas 27 cidades pesquisadas, 43,3\% dos adultos estão com sobrepeso. A incidência é maior entre os homens $(47,3 \%)$ do que entre as mulheres $(39,5 \%)$. 0 excesso de peso é diagnosticado a partir do índice de massa corporal (IMC), obtido pela razão entre o peso e o quadrado da altura. Se esse índice alcança valor igual ou superior a $25 \mathrm{~kg} /$ $\mathrm{m}^{2}$, há excesso de peso. A obesidade é diagnosticada quando o índice atinge ou supera $30 \mathrm{~kg} / \mathrm{m}^{2}$. Com $49 \%$, Porto Alegre (RS) é a capital que registra maior incidência de excesso de peso em adultos. A cidade é ainda a que reúne o maior número de obesos: 15,9\% dos adultos estão com IMC acima de $30 \mathrm{~kg} / \mathrm{m}^{2}$, enquanto Teresina (PI) apresenta a menor quantidade de pessoas acima do peso $(36,6 \%)$ e São Luís (MA), o menor número de obesos $(9,5 \%)$.

Psicol. Argum. 2014 jan./mar., 32(76), 117-127 
Embora haja um aumento da obesidade, o relatório aponta progressos na alimentação do brasileiro. Em 2006, apenas 5,6\% dos adultos consumiam a quantidade de frutas e hortaliças recomendada pela Organização Mundial de Saúde - cinco porções em cinco dias ou mais por semana. Em 2008, esse índice subiu para 15,7\% (Ministério da Saúde, 2009).

Em relação à população infanto-juvenil, a pesquisa de Orçamentos Familiares 2002-2003, realizada pelo IBGE (2006), detectou um aumento considerável na proporção de adolescentes brasileiros com excesso de peso: em 1974/1975, estavam acima do peso $3,9 \%$ dos garotos e 7,5\% das garotas entre $10 \mathrm{e}$ 19 anos; já em 2002/2003, os percentuais encontrados foram de $18 \%$ e 15,4\%, respectivamente. Entre essa população verificou-se também que a desnutrição infantil diminuiu nos últimos 30 anos, especialmente entre aqueles que, historicamente, eram mais afetados pelo problema: as crianças da região Norte e Nordeste, e as de famílias com menores rendimentos.

Lima, Arrais e Pedrosa (2004) realizaram um estudo com crianças e adolescentes com sobrepeso e obesidade e verificaram que os participantes possuíam uma alimentação inadequada, com desequilíbrio de nutrientes. Tal constatação indica a propensão ao desenvolvimento da obesidade e a instalação de outras doenças associadas a ela. A amostra do estudo possuía uma elevada ingestão de proteínas e lipídios e baixo consumo de fibras. As consequências para a manutenção desses alimentos e hábitos alimentares, especialmente na população em crescimento, são preocupantes devido ao comprometimento da saúde e da qualidade de vida.

Diante das estatísticas, alertas e transformações que a sociedade sofreu para acompanhar as mudanças na sua rotina de vida, a família, consequentemente, também precisou adaptar-se. Ao mesmo tempo, o grupo familiar possui papel fundamental na formação e no desenvolvimento dos indivíduos, e deve ser crítico e estar atento aos fatores de risco associados às mudanças nos hábitos alimentares.

\section{Alimentaç̃o e família}

A família é a unidade grupal na qual se desenvolvem três tipos de relações pessoais: aliança do casal, pais e filhos, e consanguinidade dos irmãos. A partir dos objetivos de preservar a espécie, nutrir e proteger a descendência, e fornecer elementos para a constituição da identidade, o grupo familiar desenvolveu, ao longo dos tempos, a função de transmitir valores éticos, estéticos, religiosos e culturais (Osório, 2002). A família é caracterizada, fundamentalmente, pelas relações de afeto e compromisso entre seus membros. Portanto, uma das finalidades da família seria satisfazer as necessidades básicas de seus componentes em relação aos aspectos fundamentais da sobrevivência - segurança, alimentação e um lar - e do desenvolvimento social, cognitivo e afetivo adequado (Macedo, 1994).

0 grupo familiar é o primeiro ambiente psicossocial no qual se desenvolve a personalidade de um ser humano, além de ser um modelo das relações a serem estabelecidas com o mundo. É na família que se desenvolvem as identidades pessoal e social. Dessa forma, são constituídos os sentimentos de pertinência, independência e autonomia, baseados em um processo de diferenciação, que permite a consciência de si mesmo como diferente e separada do outro (Minuchin, 1976).

A família corresponde a um grupo social que exerce notável influência sobre a vida das pessoas. Dessa forma, o ambiente familiar é considerado uma organização complexa e inserida em um contexto social mais amplo com o qual interage constantemente (Biasoli-Alves, 2004). A família segue um modelo cultural que se apresenta de maneiras diferenciadas e sofre diversas transformações no decorrer do processo histórico-social. Sendo assim, sua estrutura está fortemente relacionada ao momento histórico da sociedade da qual faz parte (Singly, 2000).

De acordo com Pratta e Santos (2007), a partir da segunda metade do século XX, a família passa por um processo de intensas transformações econômicas, sociais e trabalhistas, sobretudo nos países ocidentais. Entre esses fatores, encontram-se alguns relacionados às mudanças dentro da família (o aumento do número de separações e divórcios, a diminuição das famílias numerosas, o incremento das demandas de cada fase do ciclo vital, novas concepções em relação ao casamento, as alterações na dinâmica dos papéis parentais e de gênero) e outros relativos à sociedade (o processo de urbanização e industrialização, o avanço tecnológico, a maior participação da mulher no mercado de trabalho, a elevação do nível de vida da população, as transformações nos modos de vida e nos comportamentos das pessoas). Pelo 
emaranhado de relações ao qual família encontra-se atrelada, o que ocorreu com o ato de alimentar-se passa, inevitavelmente, pela forma que o grupo familiar assimilou o que se passou ao longo do tempo, considerando ainda suas características próprias e as de seus membros, seus símbolos e significações.

A rotina alimentar das famílias precisou ser reorganizada diante de mudanças sociais e culturais relacionadas às ocupações profissionais (horários, distâncias e a entrada da mulher no mercado de trabalho). Algumas famílias, mesmo contando com uma pessoa para elaborar suas refeições, alegam que, por falta de tempo e praticidade, precisam fazer as refeições fora de casa (Garcia, 1997).

Diversos pesquisadores (Rossi, Moreira \& Rauen, 2008; Romanelli, 2006) vêm assinalando os benefícios das refeições preparadas e partilhadas em casa em função da preservação de adequados aspectos nutricionais. Partilhar as refeições é uma oportunidade para pais e crianças considerarem preferências alimentares, planejarem menus, e de conversar sobre o dia a dia e propiciar um ambiente para modelos de atitudes sobre a comida e sobre o comer. Ao mesmo tempo, essa atmosfera propicia um sentimento de acolhimento e pode unir os membros de uma família, exercendo um papel protetivo amplo.

A alimentação originária do universo doméstico está entrelaçada com a convivência social e familiar, vinculada, principalmente, à figura materna. Consequentemente, está associada à afetividade e aos preceitos de cuidado, zelo, proteção e amor. 0 leite materno é um bom exemplo, pois é o primeiro alimento oferecido ao ser humano e sua ingestão envolve o corpo da mãe (Garcia, 1997). Callaço (2003) sugere que o lar é o primeiro referencial com o qual o indivíduo se depara para compor suas ideias a respeito do alimento, da alimentação e do ato de comer, e fornece segurança para desempenhar outros papéis além do espaço e serve como parâmetro para diferenciar um indivíduo do outro. Dessa forma possibilita a ampliação das dimensões de significados afetivos e das funções que a alimentação possui. Da Matta (1997) afirma que o lar seria um local de aconchego, descanso, reconhecimentos, sentimentos relacionados ao amor, carinho e calor humano. Além disso, a rotina e os rituais alimentares estendem a convivência familiar, proporcionam o compartilhamento de experiências, mais proximidade entre os membros da família, e ampliam assim a identidade social e a sensação de proteção frente aos relacionamentos extrafamiliares (Rotenberg \& Vargas, 2004).

As refeições em família, segundo Eisenberg et al. (2004), agiriam como uma base regular de comunicação entre pais e filhos, em que os primeiros teriam a oportunidade de perceber e monitorar as ações dos últimos, e, ao mesmo tempo, de transmitir regras e modelos de comportamento. Alguns estudos (Eisenberg et al., 2004; Eisenberg et al., 2008) sugerem que a frequência das refeições em família está inversamente relacionada com uma variedade de fatores de risco como distúrbios alimentares, atividade sexual precoce, comportamento antissocial, violência, problemas escolares e psicossociais. Além disso, essa frequência protege quanto ao início de uso de cigarros, álcool e drogas ilícitas. Tais investigações entendem que as refeições em família, em longo prazo, são protetivas em relação aos riscos anteriormente mencionados e recomendam que os pais estabeleçam um padrão de refeições familiares regulares.

A mãe ou o pai, quando prepara o alimento do filho, participa também da elaboração das percepções das preferências alimentares relacionadas diretamente aos laços familiares (Assunção, 2008). 0 alimento preparado pelos pais geralmente tem agregados um toque e um valor pessoal, carrega significados e sentimentos, ou seja, traz lembranças especiais e particulares associadas (Maciel, 2001). De acordo com Conteras (2009), as mulheres envolviam-se mais do que os homens com a tarefa de cozinhar e recebiam de suas mães e avós técnicas de preparo dos alimentos e conceitos dietéticos e de nutrição. Como exemplos de ensinamento da mãe a filhas, este autor cita o consumo de frutas e verduras para manter o corpo saudável e o uso de determinados ingredientes para preparar uma sopa. A rotina da família, ou seja, os horários dos indivíduos eram orientados pelas refeições: café da manhã, almoço e jantar. Garcia (2009) menciona o fato de que plantações de fundo de quintal e mesmo a criação de animais não eram raras, principalmente em bairros mais periféricos de grandes centros urbanos ou mesmo em cidades mais afastadas. A necessidade de abastecimento contínuo decorrente das dificuldades com a conservação e o processamento do alimento fazia dessa tarefa o centro da rotina doméstica. Entretanto, essa rotina precisou ser reorganizada de acordo com os horários do trabalho e das atividades de cada membro da família, e, como

Psicol. Argum. 2014 jan./mar., 32(76), 117-127 
consequência, as refeições tornaram-se individualizadas, o que dificultou o encontro da família nesses momentos (Garcia, 2009).

Segundo Larson (2008), poucas situações regulares da vida de adolescentes e crianças têm potencial de desenvolvimento e de perspectiva tão grande como a que acontece durante as refeições em família. $\mathrm{O}$ autor afirma que os momentos vividos pelas famílias durante as refeições ajudam no desenvolvimento linguístico das crianças, na prevenção de problemas emocionais e na diminuição dos comportamentos de risco. Nesse cenário, as crianças adquirem um vocabulário novo e participam das conversas familiares, o que aprimora também sua alfabetização. 0 mesmo autor ainda identificou em seu estudo que as refeições em ambiente doméstico geram diversas formas de comunicação positivas entre pais e filhos.

A refeição realizada e preparada em casa incorpora nos membros da família elementos como a intimidade e os investimentos afetivos, simbólicos, estéticos e econômicos. Além disso, é palco para as relações de gênero, geração e para a distribuição das atividades que traduzem as conexões com o mundo, um espaço rico em relações sociais que faz a refeição constituir-se num ritual (Santos, 2005).

Sob o ponto de vista nutricional, fazer as refeições com a família está associado à prática de hábitos alimentares mais saudáveis. Diversos estudos com adolescentes (Larson, Neumark-Sztainer, Hannan, \& Story, 2007; Larson, 2008) demonstraram que a frequência das refeições em família está relacionada a um maior consumo de frutas, vegetais, alimentos ricos em cálcio, grãos, além de menos refrigerantes. Pode-se pensar que o sistema familiar agiria como um norteador nas escolhas feitas pelos jovens que recebem apelos persuasivos dos meios de comunicação.

Em pesquisa desenvolvida por Larson (2009), a comensalidade esteve associada a hábitos de alimentação saudáveis, enquanto que o ato de alimentar-se fora de casa se mostrou relacionado a escolhas inadequadas e nocivas à saúde. 0 estudo envolveu 3.074 jovens adultos norte-americanos com idade média de 20,5 anos. A pesquisadora relatou que jovens obesos foram os que reportaram com menor frequência o compartilhamento de refeições, enquanto que aqueles dentro dos padrões normais preferiam fazer as refeições com a família, amigos e de preferência em casa. A maioria relatou a preferência por fast food ao alimentar-se fora de casa.
Conforme Fiese e Schwartz (2008), as propagandas sobre comida ocupam o segundo lugar na indústria de anúncios, só perdendo para os anúncios de automóveis. A mídia induz não só na escolha dos alimentos, mas também na maneira de comer. Em 2006, foram gastos 1,6 bilhões de dólares em propagandas direcionadas a crianças e adolescentes, entre elas de sobremesas, salgadinhos e restaurantes de fast food. No que se refere às escolhas de determinados alimentos, as crianças compõem o grupo mais vulnerável. Fiese e Schwartz (2008) afirmam que a indústria de alimentos tem criado atrativos nas embalagens direcionados ao consumidor infantil, utilizando, por exemplo, alguns itens promocionais como brindes. Percebe-se, entretanto, algumas mudanças na sociedade com o objetivo de rever as práticas alimentares. Neste processo dinâmico, o papel limitador e orientador da família é essencial.

Um estudo desenvolvido por Santos (2003), sobre o excesso de peso dos membros da família e a obesidade infantil, demonstrou que as famílias possuem informações acerca da maneira de preparar a comida, da importância da atividade física e de como colocar limites. Todavia, nota-se uma incongruência entre ter e saber a informação e os comportamentos da família. Ou seja, a família demonstra conhecimento sobre o que é alimentação saudável, mas ainda se atrapalha ao fazer escolhas.

França, Kneube e Souza-Kaneshima (2006) salientam que na adolescência podem surgir novos hábitos alimentares, um consumo que pode ser explicado por motivos psicológicos, sociais e socioeconômicos. Neste cenário de fatores da composição dos hábitos alimentares desta faixa etária, destacam-se a influência de amigos, a rebeldia contra o controle exercido pela família, a busca de autonomia ou identidade, o aumento do poder de compra, o hábito de preparar rotineiramente seu próprio alimento, a urbanização e o costume de comer fora de casa. Estes novos padrões alimentares podem repercutir na saúde futura do indivíduo maduro, bem como na escolha posterior dos alimentos.

\section{Considerações finais}

Verificou-se que diversos aspectos sociais, históricos e culturais, como guerras, o início da atividade industrial e a dinâmica das relações familiares e extrafamiliares na sociedade, trouxeram 
mudanças referentes à alimentação, tanto nas concepções e hábitos, como no comportamento das pessoas. Diversos movimentos vêm assinalando o crescente interesse pela alimentação e seu preparo e também pelos hábitos alimentares das pessoas. Um deles é a criação de confrarias entre amigos para apreciar e preparar alimentos e bebidas variados. As confrarias são grupos que emergem pela interação social e que compartilham comportamentos, afinidades, valores e modos de vida (Houaiss \& Villar, 2001). Outro indicador é a crescente busca por cursos de gastronomia, desde os de nível superior, que formam profissionais em contexto universitário, até os mais básicos, direcionados a pessoas que querem aprender a cozinhar (Freixa \& Chaves, 2008). Outros aspectos que enfatizam o interesse pelo campo da alimentação estão relacionados à criação de vários programas de televisão e obras impressas especialmente designadas a esse fim.

Apesar de todos os avanços tecnológicos, mudanças de hábitos como o rompimento da rotina de comer em grupo e o gosto padronizado das refeições rápidas, observa-se, atualmente, um retorno às cozinhas tradicionais (Fernández-Armesto, 2004). Essas transformações contradizem os números da busca pelo fast food e também põem em xeque as escolhas e preferências por este tipo de alimentação. Segundo este autor, o futuro gastronômico prevê e indica uma tendência do retorno ao passado em muitos aspectos. Pessoas que comem fora do lar têm procurado comidas caseiras e sabem que a alimentação na rua nunca poderá substituir a de casa e seus significados (Garcia, 1997). Nesse mesmo sentido, segundo Garcia e Castro (2011), o alimento preparado em casa tem a capacidade de reafirmar o pertencimento e a identidade, de transmitir afeto e outros sentimentos, mesmo quando associado a elementos de inovação, muito comuns na gastronomia contemporânea. Para o autor, por intermédio da culinária é possível preservar o passado, evocar memórias e sentimentos através de sabores e aromas.

Dada a importância da família na aquisição e manutenção dos hábitos alimentares, o elemento afetivo é central na alimentação, especialmente por implicar a relação com o outro. A refeição é um momento de encontro, de conversação e de troca de informações, isto é, de criação e manutenção de formas de sociabilidade bastante ricas e prazerosas (Romanelli, 2006). Diante de todo o exposto, verifica-se a importância da família, da cultura e da sociedade na significação e nos aspectos relacionados à alimentação. Investigações sobre essas relações permitem um melhor entendimento do que envolve o ato de alimentar-se e merecem atenção por parte da comunidade científica.

\section{Referências}

Abdala, M. C. (2009). Da casa ao restaurante: represen-tações sobre o comer fora em Minas Gerais. (pp. 5170). In N. de P. Montebello \& J. H. L. Collaço (Orgs.). Gastronomia: cortes e recortes. Brasília: Editora Senac-DF.Assunção, V. K. (2008). Comida de mãe: notas sobre ali-mentação, família e gênero. Caderno Espaço Feminino, 19(1), 233-253.

Barbosa, L. (2007). Feijão com arroz e arroz com fei-jão: o Brasil no prato dos brasileiros. Horizontes Antropológicos, 13(28), 87-116.

Bauman, Z. (2008). Vida para consumo: a transformação das pessoas em mercadorias. Rio de Janeiro: Jorge Zahar.

Biasoli-Alves, Z. M. M. (2004). Pesquisando e intervin-do com famílias de camadas diversificadas. In C. R.

Althoff, I. Elsen \& R. G. Nitschke (Orgs.). Pesquisando a família: olhares contemporâneos. (pp.91-106). Florianópolis: Papa-livro.

Brasil (2009a). Ministério da Saúde.. Vigitel Brasil 2008: vigilância de fatores de risco e proteção para doenças crônicas por inquérito telefônico. Brasília: MS.

Bezerra., \& Sichieri, I. (2010). Características e gastos com alimentação fora do domicílio no Brasil. Recuperado de http://www.scielo.br/scielo.php?script=sci_arttext\&pid=S0034-89102010000200001\&lng=en\&tln g=pt. 10.1590/S0034-8910201000020000

Collaço, J. H. L. (2003). Um olhar antropológico sobre o hábito de comer fora. Campos, 4(1), 171-193.Collaço, J. H. L. (2004). Restaurantes de comida rápida, os fast foods, em praças de alimentação de shopping centers: transformações no comer. Estudos Históricos, 33(1), 1-21.

Psicol. Argum. 2014 jan./mar., 32(76), 117-127 
Conteras, J. (2009). Os paradoxos da modernidade ali-mentar. (pp. 31-50). In N. de P. Montebello \& J. H. L Collaço (Orgs.). Gastronomia: cortes e. recortes. Brasília: Senac-DF.

Da Matta, R. (1997). A casa e a rua. Rio de Janeiro: Rocco, 1997.

Diez-Garcia, R. W., \& Castro, R. R. (2011) A culinária como objeto de estudo e de intervenção no campo da Alimentação e Nutrição. Ciência e Saúde Coletiva, 16, 91-98.

Eisenberg, M. E., Olson, R. E., Neumark-Sztainer, D., Story, \& Bearinger, L. H. (2004). Correlations between fam-ily meals and psychosocial well-being among adoles-cents. Archives Pediatric Adolescent Medicine, 158(8), 792-796.

Eisenberg, M. E., Neumark-Sztainer, D., Fulkerson, J. A., \& Story, M. (2008). Family meals and substance use: is there a long-term protective association? Journal of Adolescent Health, 43(1), 151-156.

Fernández-Armesto, F. (2004). Comida: uma história. Rio de Janeiro: Record.

Fiese, B. H., \& Schwartz, M. (2008). Reclaiming the family table: mealtimes and child health and wellbeing. Social Policy Report, 22(4), 2-9.

Freixa, D., \& Chaves, G. (2008). Gastronomia no Brasil e no mundo. Rio de Janeiro: Senac.

Garcia, R. W. D. (2003). Reflexos da globalização na cultura alimentar: considerações sobre as mudanças na alimentação urbana. Revista de Nutrição, 16(4), 483-492.

Houaiss, A., \& Villar, M.S. (2001). Dicionário Houaiss da Língua Portuguesa. Rio de Janeiro: Objetiva.

Instituto Brasileiro de Geografia e Estatística (IBGE) (2006). Pesquisa de orçamentos familiares (POF) - medidas antropométricas de crianças e adolescentes 2002/2003. Recuperado em 27 de setembro de 2011, de http://www.ibge.gov.br/home/estatistica/ popu-lacao/condicaodevida/pof/2003medidas/ default. shtm.
Larson, N., Nelson C. M., Neumark-Sztainer, D., Story, M., \& Hannan, P. J. (2009). Making Time for Meals: Meal Structure and Associations with Dietary Intake in Young Adults. Journal of the American Dietetic Association, 109, 72-79.

Larson, R. (2008). Family mealtimes as a developmental context. Social Policy Report, 22(4), 14.

Lima, S. C. V. C., Arrais, R. F., \& Pedrosa, L. F. C. (2004). Avaliação da dieta habitual de crianças e adolescen-tes com sobrepeso e obesidade. Revista de Nutrição, 17(4), 469-477.

Lobô, A. (1999). Manual de estrutura e organização do restaurante comercial. São Paulo: Atheneu.

Macedo, R. M. (1994). A família do ponto de vista psicológico: lugar seguro para crescer. Cadernos de Pesquisa, (91), 62-68.

Maciel, M. E. (2001). Cultura e alimentação ou o que têm a ver os macaquinhos de Koshima com Brillat-Savarin? Horizontes Antropológicos, 7(16), 145-156.

Malnic, B. (2008). O cheiro das coisas. Rio de Janeiro: Vieira \& Lent.

Meira, M. C. R., \& Centa, M. L. (2003). A evolução da família e suas implicações na educação dos filhos. Família, Saúde e Desenvolvimento, 5(3), 223-230.

Ministério da Saúde (2009b). Alimentação saudável para todos: siga os dez passos. Recuperado em 17 de se-tembro de 2011, de http://nutricao.saude.gov.br/ documentos /10passos_adultos.pdf.

Mintz, S. W. (2001). Comida e Antropologia: Uma breve revisão. Revista Brasileira de Ciências Sociais, (47): 31-42.

Minuchin, S. (1976). Families and Family Therapy. Cambridge: Harvard University Press.

Osório, L. C. (2002). Casais e famílias: uma visão contemporânea. Porto Alegre: Artmed.

Ornellas, L. H. (2003). A alimentação através dos tempos. Florianópolis: UFSC. 
Ortigoza, S. A. G. (1997). 0 fast food e a mundialização do gosto. Cadernos de Debate, 5(1), 21-45.

Pedrocco, G. (1998). A indústria alimentar e as novas téc-nicas de conservação, (763-778). In J. L. Flandrin \& M. Montanari (Orgs.). História da alimentação. São Paulo: Estação Liberdade.

Pitte, J. R. (1998). Nascimento e expansão dos restaurantes, (pp. 751-762). In J. L. Flandrin \& M. Montanari (Orgs.). História da alimentação. São Paulo: Estação Liberdade.

Poulain, J-P. (2004). Sociologias da Alimentação. Florianópolis: Ed. UFSC.

Pratta, E. M. M, \& Santos, M. A. (2007). Família e adoles-cência: a influência do contexto familiar no desenvol-vimento psicológico de seus membros. Psicologia em Estudo, 12(2), 247-256.

Rial, C. S. (2006). Fast-food. (pp. 187-212). In W. Araújo \& C. M. Rodrigues (Org.). Gastronomia: cortes e recortes. Brasília: Senac-DF.

Rocha, A. A. Costa, P.L. C., Neto. (2005). Educação Continuada e a distância: a formação de lideranças para o setor automotivo. In 23. Congresso Brasileiro de Ensino de Engenharia, Campina Grande. Recuperado de http://www.abenge.org. br/CobengeAnteriores / 2005 /artigos /SP-1006441807815-1118876994517.pdf

Romanelli, G., (2006). O Significado da alimentação na fa-mília: uma visão antropológica. Revista de Medicina de Ribeirão Preto, 39(3), 333-339.

Roenberg, S., \& Vargas, de S. (2004). Práticas alimentares e o cuidado da saúde: da alimentação da criança à alimentação da família. Revista Brasileira de Saúde Materno-infantil, 4(1), p 85-94.

Rossi, A., Moreira, E. A.M., \& Rauen, M. S. (2008). Determinantes do comportamento alimentar: uma revisão com enfoque na família. Revista de Nutrição, 21(6), 739-748.
Santos, A. M. (2003). O excesso de peso da família com obesidade infantil. Revista Virtual Textos \& Contextos 2(2), 1-10.

Santos, C. R. A. (2005). A alimentação e seu lugar na história: os tempos da memória gustativa. História: Questões \& Debates, 42(1), 11-31.

Santos, C. R. A. (2009). O lugar da alimentação na histó-ria. In N. de P. Montebello \& J. H. L. Collaço (Orgs.). Gastronomia: cortes e recortes (pp.81-96). Brasília: Senac-DF.

Silva, J. L. M (2007). Transformações no espaço doméstico: o fogão à gás e a cozinha paulistana, 1870-1930. Anais do Museu Paulista, 15(2), 197-220.

Singly, F. (2000). O nascimento do "indivíduo individuali-zado" e seus efeitos na vida conjugal e familiar. In C. Peixoto, F. de Singly, \& V. Cicchelli (Orgs.). Família e individualização (pp.13-19). Rio de Janeiro: FGV.

Soares, J. C. (2004). McDonalização e Hipermodernidade: O mito do "Mc Lanche Feliz". Recuperado de http:// encipecom.metodista.br/mediawiki/images/0/00/ GT7-texto5-_Macdonalizacao_-_Jorge.pdf

Souza, N. I. (2001). Aliment'Arte: uma nova visão sobre o alimento e sua produção. São Paulo: Livraria.

Strong, R. C. (2004). Banquete: uma história ilustrada da culinária dos costumes e da fartura à mesa. Rio de Janeiro: Jorge Zahar.

Viana, V. (2002). Psicologia, saúde e nutrição: contributo para o estudo do comportamento alimentar. Análise Psicológica, 4, 611-624.

Psicol. Argum. 2014 jan./mar., 32(76), 117-127 